\title{
Q1a3a native-American Y-haplogroup detection in DNA quantification step: A quick diagnosis for Y-chromosome database selection
}

\author{
S. Ginart ${ }^{\mathrm{a}, \mathrm{b}}$, , M. Caputo ${ }^{\mathrm{a}, \mathrm{b}}$, D. Corach $^{\mathrm{a}, \mathrm{b}}$, A. Sala ${ }^{\mathrm{a}, \mathrm{b}}$ \\ ${ }^{a}$ Universidad de Buenos Aires - Facultad de Farmacia y Bioquímica, Departamento de Microbiología- Inmunología- Biotecnología y Genética. Centro de Referencia en \\ Identificación Genética Humana, Cátedra de Genética Forense y Servicio de Huellas Digitales Genéticas (SHDG), Junin 956, Ciudad Autónoma de Buenos Aires, 1113, \\ Argentina \\ ${ }^{\mathrm{b}}$ Consejo Nacional de Investigaciones Científicas y Técnicas-Conicet, Argentina
}

\section{A R T I C L E I N F O}

\section{Keywords:}

Q1a3a native-American Y-haplogroup

DNA quantification

Y-STR haplotype databases

SNPs

High resolution melting

\begin{abstract}
A B S T R A C T
We present the optimization of a previously developed DNA quantification approach that now makes possible the simultaneous detection of Q1a3a Native-American Y-chromosome haplogroup by means of real time-PCR followed by high resolution melting (HRM) analysis. Genotyping is possible by differences in melting temperature (Tm) of one specific Y-chromosome fragment (58bp long, included in the reaction cocktail) which contains the M3-Q3 C/T polymorphism. The specific variant M3-Q3/T (Native-American lineage) has a Tm $\approx$ $76^{\circ} \mathrm{C}$, whereas M3-Q3/C (non-Native-American) has $\mathrm{Tm} \approx 77^{\circ} \mathrm{C}$. Fifty reference male DNA samples (blood and muscle from autopsy) were analyzed. DNA concentration ranged from 0,01 to $28 \mathrm{ng} / \mu \mathrm{L}$. Thirteen showed NativeAmerican signature $\left(\mathrm{Tm}_{\mathrm{T}}=76,02 \pm 0,04\right)$ while thirty-seven as non-Native-American $\left(\operatorname{Tm}_{\mathrm{C}}=77,13 \pm 0,06\right)$. These results were compared to those predicted from Y-STRs by White Athey's on-line software. Casework samples containing male DNA were quantified and successfully haplogrouped. The STRs profiles, subsequently obtained, correlated well with quantitation results. This system represents an approach that provides valuable information at early stages of genotyping process, and useful for choosing the most suitable Y-chromosome database for statistical evaluations.
\end{abstract}

\section{Introduction}

Previous developments of quantification systems allowed us to obtain an efficient tool to simultaneously quantify human DNA, detect male DNA and estimate DNA degradation in one real time PCR reaction followed by high resolution melt (HRM) using Syto9 chemistry [1-3]. Farther optimization of this approach allowed us to obtain additional information for screening purposes. The possibility of obtaining genetic data of forensic relevance in early stages of the genotyping process is a key aspect to determining the most appropriate workflow: marker selection, sample volume, DNA amplification cycling and capillary injection protocols. Nowadays, human DNA quantification kits simultaneously provide information about gender and DNA degradation extent, but none supply information concerning genetic ancestry. Ancestry informative markers (AIMs) can provide valuable information in forensic casework [4]. The knowledge of ancestral genetic information of a male contributor to a forensic sample can provide investigative clues such as assessing population of origin of the sample donor. However, this genetic data is available after SNPs or Indels amplification and capillary electrophoresis (CE) detection. Our development was improved and now can discriminate Native American Y-chromosome lineage from non-Native American haplogroup. Q1a3a Native-American Y-haplogroup (NA-Y-hg) is defined by the transition C/T at M3-Q3 SNP [5]. In this work we show how NA-Y-hg is diagnosed in the quantification step by high resolution melting by analyzing reference samples and evidences derived from real-life casework.

\section{Materials, methods and techniques}

\subsection{Samples}

Plexor $^{\circledR}$ HY Male Genomic Standard DNA was used as male control DNA to set up PCR conditions and test sensitivity, precision and calibration curves reproducibility in five independent runs. Reference DNA: human male muscle from autopsy and blood; saliva from human female donor as female control. Evidence DNA: swabs and piece of clothes derived from casework. NA-Y-hg control: blood from a Q1a3a Y-hg male donor. Non NA-Y-hg control: blood from $R 1 b$ Y-hg male donor

\footnotetext{
* Corresponding author at: Junin 956, Piso 7, 1113 Ciudad autónoma de Buenos Aires, Argentina.

E-mail address: sginart@ffyb.uba.ar (S. Ginart).
} 

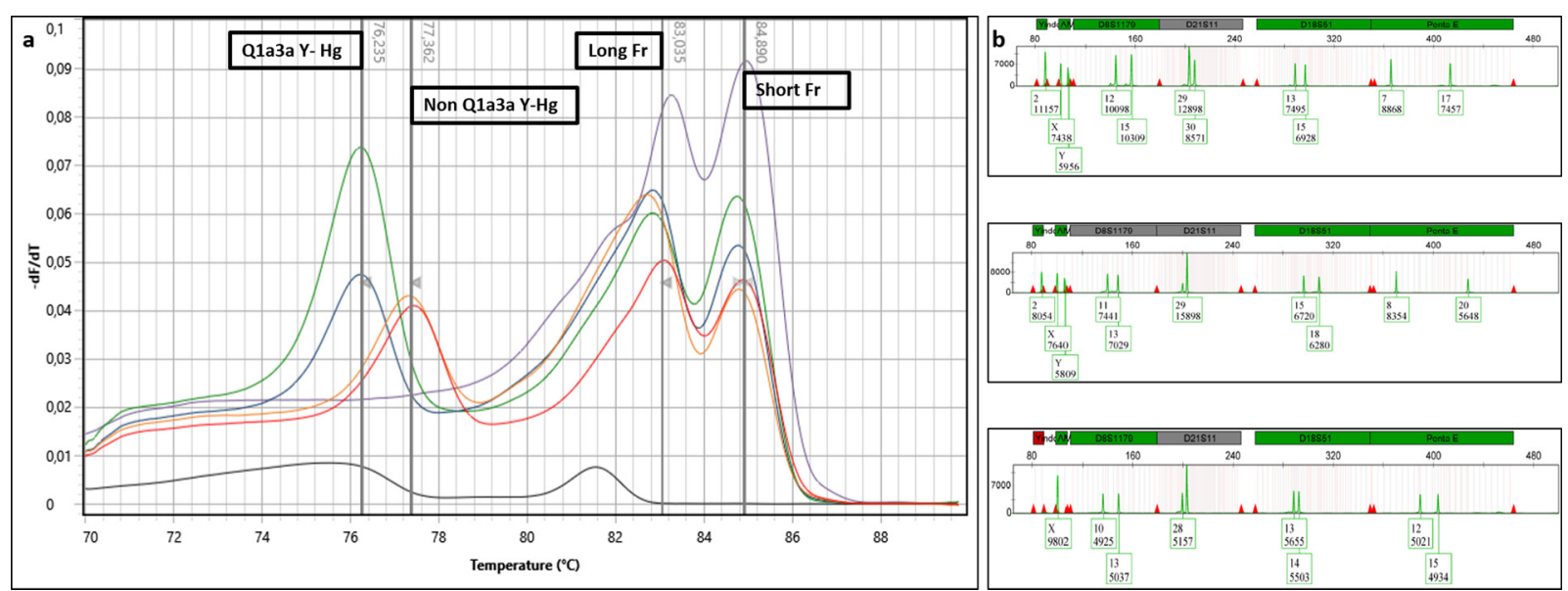

Fig. 1. a) Derivative Melt Curves Plot. Blue: Native-American Y-hg control ( $0.62 \mathrm{ng} / \mu \mathrm{L})$; Orange: R1b Y-hg control $(0.34 \mathrm{ng} / \mu \mathrm{L})$; Violet: female DNA (1 ng/ $\mu \mathrm{L})$; Green: male 1 DNA (6.70 ng/ $\mu \mathrm{L})$; Red: male 2 DNA $(0.13 \mathrm{ng} / \mu \mathrm{L})$; Black: Negative control. b) STRs results (VIC ${ }^{\mathrm{TM}}$ dye channel): From top to bottom male 1 , male 2 and female DNAs, respectively. Fr.: autosomal fragment (For interpretation of the references to colour in this figure legend, the reader is referred to the web version of this article).

(R1b is the most frequent non-NA-hg in Argentina).

\subsection{DNA extraction}

Performed with Maxwell instrument (Promega Corp. Madison, USA) according to manufacturer's instructions

\subsection{Reagents and amplification conditions}

$25 \mu \mathrm{L}$ final volume: $37.5 \mathrm{pmol}$ Syto9(Invitrogen, USA), 1.25 units GoTaq DNAPolymerase, 5X Colorless GoTaq Reaction Buffer, $3.75 \mu \mathrm{mol}$ 4dNTPs mix (Promega), $1.7 \mathrm{mM} \mathrm{Mg}^{2+}$ and $2 \mu \mathrm{L}$ sample DNA. Primers: 8.5 pmol Y-chromosome amplicon [6], 10 pmol short autosomal amplicon [2] ; 12.5 pmol long autosomal amplicon [2]. qPCR platform: Mic qPCR Cycler (Bio Molecular Systems ${ }^{\odot}$ Australia). Cycling conditions: $94^{\circ} \mathrm{C} 2$ min.; 37 cycles of $94^{\circ} \mathrm{C} 15$ seg., $57^{\circ} \mathrm{C} 30$ seg. and $72{ }^{\circ} \mathrm{C} 30$ seg.; Melt from $70{ }^{\circ} \mathrm{C}$ to $90^{\circ} \mathrm{C}$ at $0,1{ }^{\circ} \mathrm{C} / \mathrm{seg}$.

\subsection{DNA quantification}

The threshold cycle corresponding to the total fluorescence produced by the amplicon* is determined for each sample. A calibration curve (50-0.016 $\mathrm{ng} / \mu \mathrm{L}$ male Standard DNA) is amplified in parallel to calculate the corresponding concentration $(\mathrm{ng} / \mu \mathrm{L})$. *Male DNA: 3 fragments (Y-chromosome/ short autosomal/ long autosomal) Female DNA: 2 fragments (short autosomal/long autosomal) Short Tandem Repeats markers (STRs) and Capillary Electrophoresis Autosomal STRs: VeriFiler $^{\mathrm{TM}}$ Express PCR Amplification Kit (Applied Biosystems ${ }^{\mathrm{TM}}$ ). Ychromosome STRs: PowerPlex ${ }^{\circledast}$ Y23 System (Promega). Cycler: Veriti ${ }^{\circledR}$ 96-Well Thermal Cycler (Applied Biosystems ${ }^{\mathrm{TM}}$ ). PCR amplifications were performed according manufacturer protocol.

\subsection{Software analysis}

Mic qPCR Cycler software v.2.6.5 (Bio Molecular Systems ${ }^{\odot}$ ). Genemapper $^{\circledast}$ IDX v.1.5. (Applied Biosystems ${ }^{\mathrm{TM}}$ ). White Athey's haplogroup predictor (http://www.hprg.com/hapest5/hapest5a/hapest5. htm).

\section{Results}

Q1a3a Y-hg detection was made by means of HRM by typing M3-Q3 $\mathrm{C} / \mathrm{T}$ SNP in which Thymine variant (NA-Y-hg) has specific melting temperature $(\mathrm{Tm})$ at $\approx 76{ }^{\circ} \mathrm{C}$ and Cytosine variant (non NA Y-hg) has a
$\mathrm{Tm} \approx 77^{\circ} \mathrm{C}$. The system was able to amplify standard DNA from 50 to $0.016 \mathrm{ng} / \mu \mathrm{L}$. Calibration curves showed good performance in five independent runs since the reaction slope $(\mathrm{m})$ mean value $=3.317 \pm$ 0.055 . Fifty male reference samples were quantified and ranged from 0.01 to $28 \mathrm{ng} / \mu \mathrm{L}$. Thirteen were characterized as Native-American $\left(\mathrm{Tm}_{\mathrm{T}}=76.02 \pm 0.04\right)$ while thirty-seven as non-Native-American $\left(\mathrm{Tm}_{\mathrm{C}}=77.13 \pm 0.06\right)$. These results were contrasted with Y-STRs/ White Athey's haplogroup predictor and both methods agreed (Supplementary table). Fig. 1a shows melting profiles of DNAs controls, males and female donors and how Q1a3a NA-Y-hg is discriminated. Long and short autosomal fragments melting peaks $\left(\mathrm{Tm} \approx 83^{\circ} \mathrm{C}\right.$; $\mathrm{Tm} \approx$ $84.8^{\circ} \mathrm{C}$, respectively) are useful as quality indicators of DNA integrity [2]. The ability to generate quality genetic profiles was demonstrated by STRs results obtained after DNA markers amplification where DNA template was normalized according to the quantification results of this tool (Fig. 1b).

The analysis of DNA from evidence samples reveal the usefulness of this diagnostic tool for Y-hg determination in challenging casework samples: low DNA concentration, degraded DNA and mixture samples where proportion of female component is greater than the male one (Supplementary figure).

\section{Discussion}

We developed an HRM assay for detecting the Q1a3a haplogroup, the Native-American Y signature. It is included in the same reaction of DNA quantification and DNA degradation assessment step. Since the melting temperature of the M3-Q3 SNP differs in $1{ }^{\circ} \mathrm{C}$ compared to that shown by the non-NA-Y-hg, it constitutes a reliable approach to identify Amerindian male signature in an early experimental step. The amplified Y-amplicon is as small as $58 \mathrm{bp}$, therefore it would be potentially useful to make the diagnosis in highly degraded DNA where conventional YSTRs failed. Moreover, time is saved compared to the use of online haplogroup predictors that require Y-STRs amplification and each of the allelic variants to be loaded into the on-line program. We propose this system as a quick tool to detect Q1a3a haplogroup in forensic samples for assisting in the selection of the most suitable Y-chromosome database to avoid sub or over estimation of the corresponding Y-STRs haplotype frequency.

\section{Conclusion}

We have incorporated a new determination into a previously developed quantification system. As far as we know is the first DNA 
quantification approach applicable to forensic casework that provides ancestry data specific for male's donors. We suggest HRM analysis to be employed in quantification step as an alternative method to detect relevant genetic data in the forensic arena to better define the best genotyping strategy to be adopted. It is a fast and sensitive tool that avoids multi-tube operation. It is cost-effective and compatible with any realtime platforms that allows melting analysis.

\section{Declaration of Competing Interest}

The authors declare that they have no conflicts of interest.

\section{Acknowledgements}

This work was supported, in part, by grants 20020170100721BAUBACyTand genuine funds generated by SHDG. MC, AS and DC are members of the CIC-Conicet. SG is a Conicet doctoral fellow.

\section{Appendix A. Supplementary data}

Supplementary material related to this article can be found, in the online version, at doi:https://doi.org/10.1016/j.fsigss.2019.09.119.

\section{References}

[1] S. Ginart, M. Caputo, E. Alechine, D. Corach, A. Sala, Development of a quantitation approach for total human and male DNA based on real time PCR followed by high resolution melting analysis, Electrophoresis 37 (2016) 2734-2741, https://doi.org/ 10.1002/elps.201600185.

[2] S. Ginart, M. Caputo, D. Corach, A. Sala, Human DNA degradation assessment and male DNA detection by quantitative-PCR followed by high-resolution melting analysis, Forensic Sci. Int. 295 (2019) 1-7, https://doi.org/10.1016/j.forsciint.2018.11. 013.

[3] S. Ginart, M. Caputo, D. Corach, A. Sala, Measuring human DNA degradation and gender detection in forensic DNA samples by q-PCR/HRM analysis, Forensic Sci. Int. Genet. Suppl. Ser. 6 (2017) e552-e554, https://doi.org/10.1016/j.fsigss.2017.09. 211.

[4] R. Pereira, C. Phillips, N. Pinto, C. Santos, S.E.B. dos Santos, A. Amorim, Á. Carracedo, L. Gusmão, Straightforward inference of ancestry and admixture proportions through ancestry-informative insertion deletion multiplexing, PLoS One (2012), https://doi.org/10.1371/journal.pone.0029684.

[5] P.A. Underhill, L. Jin, R. Zemans, P.J. Oefner, L.L. Cavalli-Sforza, A pre-Columbian Y chromosome-specific transition and its implications for human evolutionary history, Proc. Natl. Acad. Sci. (2002), https://doi.org/10.1073/pnas.93.1.196.

[6] G. Zuccarelli, E. Alechine, M. Caputo, C. Bobillo, D. Corach, A. Sala, Rapid screening for Native American mitochondrial and Y-chromosome haplogroups detection in routine DNA analysis, Forensic Sci. Int. Genet. (2011), https://doi.org/10.1016/j. fsigen.2010.08.018. 